\title{
HIV-1 subtype C dissemination in southern Brazil
}

\author{
Esmeralda A.J.M. Soaresa , Ana M.B. Martínez ${ }^{\text {, }}$, Thatiana M. Souza a , \\ André F.A. Santos ${ }^{a}$, Vanusa Da Horab , Jussara Silveirab, Francisco I. \\ Bastos $^{c}$, Amilcar Tanuri ${ }^{\mathrm{a}}$ and Marcelo A. Soares ${ }^{\mathrm{a}}$
}

\begin{abstract}
Objectives: To describe the molecular and epidemiological profile of HIV-1 in patients followed at the University Hospital of Rio Grande, Brazil.

Design and methods: A cross-sectional study was conducted from September to December 2002. Plasma viral RNA of 85 patients was extracted and protease and reverse transcriptase genes were polymerase chain reaction-amplified and sequenced. Sequences were subtyped and examined to antiretroviral resistance mutations. Laboratory data and past history of antiretroviral treatment were also collected.

Results: Most viruses were either subtype B (42\%) or subtype C (45\%). No risk behaviour, sexual orientation or laboratory parameter was associated with any specific subtype, but subtype $C$ tended to be more frequently found in women $(P=0.06)$. The prevalence of subtype $C$ has increased over the HIV/AIDS epidemic, accounting for almost $60 \%$ of cases diagnosed in 2002. Intra-subtype genetic distances were smaller in subtype $C$ than in subtype $B$, suggesting a more recent introduction of the former in the epidemic. Of patients under treatment, $60 \%$ had at least one antiretroviral drug resistance mutation, but no mutation was specifically associated with any HIV-1 subtype. Only one resistance mutation each was found in drug-naive patients with subtypes B and C.

Conclusion: Despite the fact that subtype $\mathrm{C}$ appeared in southern Brazil more recently than subtype B, it is now the predominant strain in Rio Grande. The epidemic spread of subtype $C$ could be taking place in Brazil, and possibly in south America, a phenomenon similar to that seen in other countries where this subtype is now totally dominant.

(c) 2005 Lippincott Williams \& Wilkins
\end{abstract}

AIDS 2005, 19 (suppl 4):S81-S86

Keywords: HIV-1, molecular epidemiology, southern Brazil, subtype C

\section{Introduction}

HIV-1 of subtype $\mathrm{C}$ is currently the most prevalent virus subtype and it is found in more than $56 \%$ of HIV infections worldwide [1]. Subtype B prevails in the developed countries of western Europe and the United States where HIV infections are concentrated in high-risk populations such as men who have sex with men and injection drug users [2]. Subtype C is more prevalent in countries with high HIV infection rates among heterosexuals, such as those of sub-Saharan Africa [38] and the populous countries of India and China [9-12]. It is believed that subtype $\mathrm{C}$ has risen above other previously prevalent subtypes in these regions [13,14]. In Brazil, although subtype $\mathrm{B}$ is still more common nationwide, subtype $\mathrm{C}$ has been increasingly prevalent in the southern region $[15,16]$. Although regional studies have suggested an increase in subtype $\mathrm{C}$, such studies were carried out in state capitals and did not assess the inland spread of the HIV epidemic characteristic of Brazil [17].

The city of Rio Grande is located in the outermost southern Brazil, near the Uruguayan and Argentine borders. The economy of Rio Grande is based on port activity and ships from Africa and Asia arrive at its local harbours. A study carried out in this city revealed a $22 \%$

From the a Laboratório de Virologia Molecular, Universidade Federal do Rio de Janeiro, Rio de Janeiro, RJ, the ${ }^{\mathrm{b}}$ Departamento de Patologia, Fundação Universidade Federal do Rio Grande, RS and the 'Instituto Oswaldo Cruz, Rio de Janeiro, RJ, Brazil.

Correspondence to Marcelo A. Soares, Laboratório de Virologia Molecular, Universidade Federal do Rio de Janeiro, CCS-BL.ARM.A2-121, Cidade Universitária, Ilhado Fundás, 21949-570, Rio de Janeiro, RJ, Brazil.

Tel: +55 212562 6384; fax: +55 212562 6396; e-mail: masoares@biologia.ufrj.br 
point prevalence of subtype C in 1997 [18]; however, less is known about the temporal trends in the prevalence of subtype $\mathrm{C}$, its geographical distribution and the potential contribution of Brazil to the spread of subtype $\mathrm{C}$ virus in South America.

The present study aims to describe the molecular and epidemiological profile of HIV-1 in the city of Rio Grande, in the state of Rio Grande do Sul. The distribution dynamics of virus subtypes at different times throughout the HIV/AIDS epidemic is described as well as the spread of their genetic diversities in the study population. Finally, the universal availability of antiretroviral drugs in Brazil also made it possible to examine the genotypic resistance of subtype C to treatment, a phenomenon rarely studied elsewhere in the world.

\section{Materials and methods}

\section{Study population and sample collection}

A consecutive sample of 100 HIV-positive patients routinely seen at the HIV/AIDS outpatient clinic of the University Hospital of Rio Grande participated in the study from September to December 2002. Upon informed consent (provided by $100 \%$ of those invited), a plasma specimen was collected and existing medical records were reviewed. The University Hospital is the only public health centre providing care to HIV-positive patients in Rio Grande and the surrounding cities and it is a reference centre in the southern part of the state of Rio Grande do Sul. Currently, approximately 1200 patients are now followed in that centre. Study inclusion criteria included age more than 18 years, available past and current medical records, laboratory tests (viral load and CD4 T-cell counts) and date of HIV diagnosis. Patients diagnosed between 1988 and 2002 were included. For each patient, a standardized data abstraction form recorded the date of diagnosis, the last 15 CD4 T-cell counts and HIV viral load estimations, clinical information and past and current antiretroviral treatment regimens and their duration was compiled.

Plasma was separated at the Federal University of Rio Grande (FURG) Laboratory of Molecular Biology, and approximately $1 \mathrm{ml}$ was sent packed in dry ice to the Federal University of Rio de Janeiro (UFRJ) Laboratory of Molecular Virology for subsequent processing. At UFRJ, plasma was stocked at $-70^{\circ} \mathrm{C}$ until further processing.

\section{Viral RNA extraction, polymerase chain-reactions and sequencing}

As previously described [19], viral RNA was extracted from plasma and complementary DNA synthesis was immediately carried out with random primers. Polymerase chain reactions (PCR) were conducted in two steps with specific nested primers. The entire gene of the protease region (PR) and the first 225 codons of reverse transcriptase (RT) were amplified, purified using the Qiagen kit (Qiagen, Valencia, California, USA) and sequenced in an automated ABI 3100 sequencer (Applied Biosystems, Foster City, California, USA). Sequencing chromatograms were aligned in PC/Windows using SeqMan software (DNAStar, Madison, Wisconsin, USA) and manually edited.

Of 100 samples processed for PCR and sequencing, molecular information on one of the genomic regions (PR or RT) was obtained from 85 cases. Thirty-six (42\%) had both regions analysed, whereas 23 (27\%) had only PR and $26(31 \%)$ had only RT available for analysis. Most of the remaining 15 samples $(11 / 15 ; 73 \%)$ were from subjects under treatment with undetectable plasma viral loads ( $<80$ copies of viral RNA per millilitre of plasma) and thus were not able to be included in the analysis.

\section{Phylogenetic and drug resistance mutation analyses}

The corresponding sequences to PR and RT genes were aligned to reference sequences representative of all HIV-1 subtypes obtained from the Los Alamos database (http:// hiv-web.lanl.gov) in ClustalW [20]. Aligned sequences were subjected to phylogenetic inference through the neighbour-joining method and Kimura 2-parameter model of the MEGA 2.1 package [21] for the inference of HIV-1 subtypes. Mean genetic distances of subtype C and B samples were determined using the Li93 method [22] of the MEGA 2.1 package [21]. The genotypic interpretation of antiretroviral drug-resistant mutations in the PR and RT genes was carried out through electronic submission to the Stanford database (http://hivdb.stanford.edu) [23]. Mutations were gathered according to the International AIDS Society-USA consensus statement [24]. Gene sequences obtained in the study were submitted to the GenBank database and were assigned the access numbers DQ190951 - DQ191039.

\section{Statistical analyses}

Continuous variables (age, time from diagnosis, CD4 T-cell counts and $\log _{10}$ HIV viral loads) were compared between subtype B and C groups using Student's $t$-tests. Categorical variables [sex, exposure categories, Centers for Disease Control and Prevention (CDC) clinical and immunological stages and treatment status] were compared using the chi-squared test with Yates' correction. Temporal trends of subtype prevalence over the epidemics were evaluated by chi-squared for trend.

\section{Results}

\section{Epidemiological features}

Table 1 shows the demographic characteristics, risk category, laboratory and molecular markers and treatment status of the 85 patients with virus molecular information. 
Table 1. HIV subtypes by demographic, clinical, and laboratory characteristics among patients of University Hospital of Rio Grande, Rio Grande, Brazil, 2002.

\begin{tabular}{|c|c|c|c|}
\hline & Total $(n=85)$ & Subtype B $(n=36)$ & Subtype C $(n=38)$ \\
\hline Mean age (years) $\pm S D$ & $35.2 \pm 11.0$ & $37.3 \pm 11.5$ & $32.9 \pm 10.1$ \\
\hline \multicolumn{4}{|l|}{$\operatorname{Sex}(\%)$} \\
\hline Male & $45(53 \%)$ & $24(67 \%)$ & $16(42 \%)$ \\
\hline Female & $40(47 \%)$ & $12(33 \%)$ & $22(58 \%)$ \\
\hline Mean diagnosis time (years) $\pm \mathrm{SD}$ & $3.4 \pm 3.1$ & $3.6 \pm 3.0$ & $2.8 \pm 2.5$ \\
\hline \multicolumn{4}{|l|}{ Exposure categories } \\
\hline Homo/bisexual & $15(18 \%)$ & $8(22 \%)$ & $5(13 \%)$ \\
\hline Heterosexual & $50(59 \%)$ & $19(52 \%)$ & $27(71 \%)$ \\
\hline Injection drug user & $15(18 \%)$ & $5(14 \%)$ & $6(16 \%)$ \\
\hline Haemophiliac/transfusion & $2(2 \%)$ & $2(6 \%)$ & 0 \\
\hline Unknown & $3(3 \%)$ & $2(6 \%)$ & 0 \\
\hline \multicolumn{4}{|l|}{ CDC clinical stage (\%) } \\
\hline A & $29(37 \%)$ & $12(36 \%)$ & $16(47 \%)$ \\
\hline $\mathrm{B}$ & $17(22 \%)$ & $6(18 \%)$ & $8(24 \%)$ \\
\hline $\mathrm{C}$ & $32(41 \%)$ & $15(45 \%)$ & $10(29 \%)$ \\
\hline Non-identified & 7 & 3 & 4 \\
\hline \multicolumn{4}{|l|}{ CDC immunological stage (\%) } \\
\hline 1 & $14(16 \%)$ & $5(14 \%)$ & $8(21 \%)$ \\
\hline 2 & $43(51 \%)$ & $20(56 \%)$ & $19(50 \%)$ \\
\hline 3 & $28(33 \%)$ & $11(31 \%)$ & $11(29 \%)$ \\
\hline \multicolumn{4}{|l|}{ Mean CD4 T-cell count (SD) } \\
\hline Treated & $246(157)$ & $254(167)$ & $265(167)$ \\
\hline Non-treated & $395(260)$ & $520(426)$ & $375(195)$ \\
\hline \multicolumn{4}{|l|}{ Median $\log _{10}$ of viral RNA } \\
\hline Treated log & 3.7 & 3.5 & 4.0 \\
\hline Non-treated log & 3.9 & 3.6 & 3.9 \\
\hline \multicolumn{4}{|l|}{ Treatment status (\%) } \\
\hline Treated & $48(56 \%)$ & $25(69 \%)$ & $15(40 \%)$ \\
\hline Non-treated & $25(29 \%)$ & $6(17 \%)$ & $19(50 \%)$ \\
\hline Interrupted treatment & $12(14 \%)$ & $5(14 \%)$ & $4(10 \%)$ \\
\hline
\end{tabular}

CDC, Centers for Disease Control and Prevention. All statistical comparisons were not significant unless otherwise stated in the text.

The mean age was 35 years, men-to-women ratio was $1: 1$, and the mean estimated length of HIV diagnosis was 3.4 years. Of all patients, $41 \%$ were in clinical stage $\mathrm{C}$ and $33 \%$ in immunological stage 3 according to CDC criteria at the time of sample collection. Fifty-six per cent of patients were under antiretroviral drug treatment, whereas the remainder did not meet the Brazilian criteria for receiving drug treatment (www.aids.gov.br/final/biblioteca/adulto_2004/consenso.doc) and thus were treatment-naive or had received treatment in the past but were not under treatment at the time of sample collection.

\section{HIV-1 subtype profile}

Phylogenetic analysis of viral PR and RT determined that $45 \%$ of the samples were subtype C, $42 \%$ were subtype B, $5 \%$ were subtype $\mathrm{F} 1,2 \%$ were subtype $\mathrm{D}$, and $6 \%$ were recombinant samples (three $\mathrm{F} 1 / \mathrm{B}$, one $\mathrm{D} / \mathrm{B}$, and one $\mathrm{B} / \mathrm{C})$. Of note is the fact that the $\mathrm{B} / \mathrm{C}$ recombinant found was from a recently diagnosed individual. Subtypes C and B comprised almost $90 \%$ of studied samples, and demographic and laboratory data from these samples were compared separately (Table 1, columns 3 and 4). The mean age, mean length of diagnosis, exposure category, clinical stage, CD4 T-cell counts, viral load and treatment status were similar in the groups of patients infected with subtypes B and C, and no statistically significant differences were found. However, a marginal significance was seen in the sex proportion for both subtypes; subtype $\mathrm{C}$ was more frequently seen in women $(P=0.03$, nonadjusted chi-squared test; $P=0.06$ after Yates' correction). An apparent difference was observed between patients classified according to CDC clinical staging, although such a difference did not reach statistical significance. Forty-five per cent of the subtype B group were stage C, whereas $47 \%$ of the subtype $\mathrm{C}$ group were stage A (Table 1). With regard to treatment, $69 \%$ of the subtype B group had already undergone previous treatment or were currently under treatment compared with $40 \%$ of the subtype $\mathrm{C}$ group $(P=0.02$, chi-squared test after Yates' correction).

\section{Dynamics of HIV-1 subtypes throughout HIV/AIDS epidemic}

Despite being equally represented in the sample overall, there was a tendency towards an increasing proportion of subtype $\mathrm{C}$ over subtype $\mathrm{B}$ over time. Figure 1 shows an increasing relative proportion of subtype $\mathrm{C}$ from $36 \%$ of cases before 1997 to $58 \%$ of cases in 2002. However, this trend was not statistically significant $(P=0.18$, chisquared test for trend). 


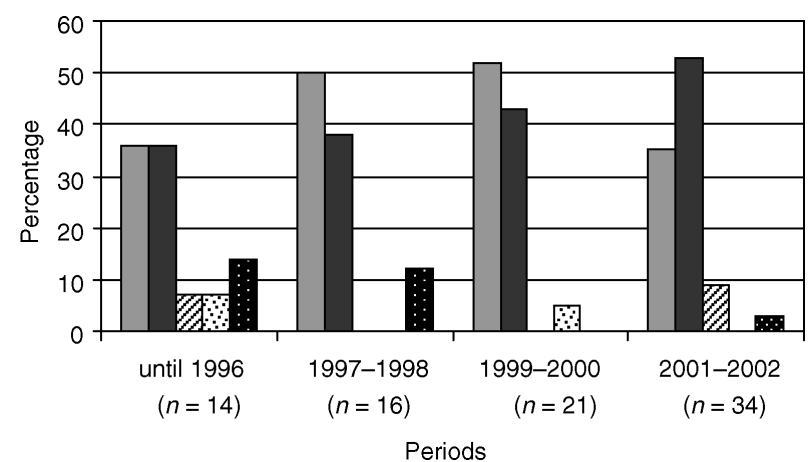

Fig. 1. HIV-1 subtype proportions according to diagnosis period, Rio Grande, Brazil, 1988-2002. $\square$ B; $\square$ C; 四 F1; 图 D; a mosaic.

In order to corroborate the hypothesis of a more recent introduction of subtype $\mathrm{C}$ in the region, mean genetic distances in PR and RT sequence groups were compared between subtypes B and C. The mean sequence distance in $\mathrm{PR}$ of the subtype $\mathrm{C}$ group was $4.2 \%$ (SE $0.5 \%$ ) at nucleotide level compared with 7.3\% (SE 0.8\%) in the subtype B group (Fig. 2a). As for RT, subtype C sequences showed a mean distance of $5.9 \%$ (SE 0.5\%) compared with 6.2\% (SE 0.5\%) seen in subtype B (Fig. $2 \mathrm{~b})$. The mean distance differences in PR were highly

(a)

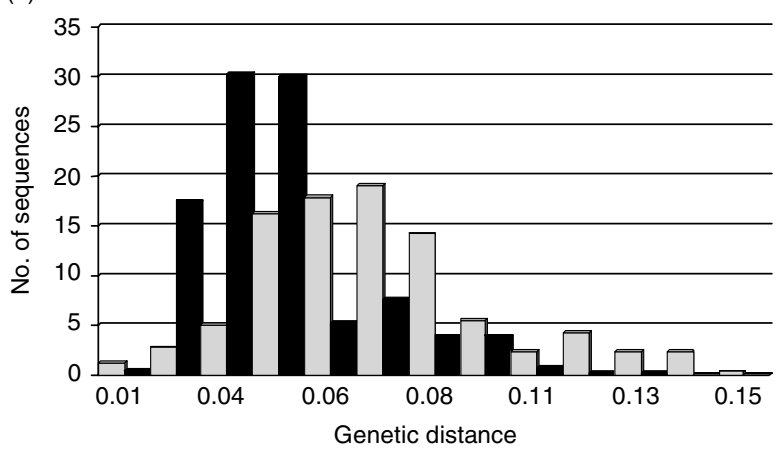

(b)

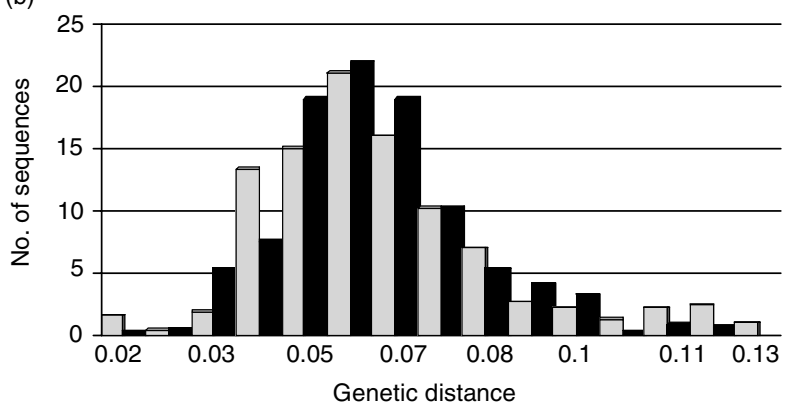

Fig. 2. Interpatient pairwise genetic distances between protease and reverse transcriptase sequences of subtypes $B$ and C, Rio Grande, Brazil, 1988-2002. (a) Protease sequences of subtypes B ( $\square$ ) and C ( $\square$ ). (b) Reverse transcriptase sequences of subtypes B ( $\square$ ) and C ( $\mathbf{\square}$ ). significant $(P<0.001$, Student's $t$-test $)$ whereas the difference in RT means was borderline $(P=0.07)$.

\section{Profile of genotypic resistance to antiretroviral drugs}

The availability of antiretroviral drug treatment in Brazil since 1987 and the highly active antiretroviral therapy with PR inhibitors since 1996 has made the southern region an attractive area for studying the subtype $\mathrm{C}$ virus response to treatment. Among patients currently under any antiretroviral drug treatment $(n=48), 57 \%$ had at least one resistance mutation to RT nucleoside analogues. Of those receiving RT non-nucleoside inhibitors as part of their current regimens, $54 \%$ had at least one mutation for these drugs. Of those receiving protease inhibitors (PI, $n=33$ ), $38 \%$ had at least one primary PI mutation. We found no specific association between HIV-1 subtypes and specific resistance mutations (data not shown). Of the treatment-naive patients $(n=25)$, only one subtype B sample had a PI L90M mutation and one subtype C sample had a V82I mutation.

\section{Discussion}

Our study shows a high prevalence of HIV-1 subtype C in Rio Grande, a port city that borders other south American countries. The temporal trend analysis of HIV subtype distribution among diagnosed cases throughout the epidemics showed that subtype $\mathrm{C}$ has prevailed over subtype $B$, which used to be more prevalent.

Several lines of evidence in our study point towards an increase in subtype $\mathrm{C}$ in southern Brazil. An increasing proportion of subtype $\mathrm{C}$ over time in the epidemics, the younger age of subtype C-infected individuals, the shorter time of diagnosis for those subjects, less advanced clinical and immunological stages in the subtype $\mathrm{C}$ group, a smaller proportion of subtype C-infected subjects under treatment and genetic variation in the pol gene all argue in favour of a more recent introduction and expansion of this subtype. Although some of this evidence is not statistically significant or is of borderline significance, taken together they support such a hypothesis.

The recent predominance of subtype $\mathrm{C}$ over other subtypes has been described in many countries [4-12], and has also recently been described by our group in the city of Porto Alegre, the state capital of Rio Grande do Sul [14]. However, we now report an even higher prevalence in the city of Rio Grande. Furthermore, a separate study in the city of Rio Grande among HIVinfected women in labour found the percentage of subtype $\mathrm{C}$ to be greater than $70 \%$ [25]. These findings 
support the hypothesis that subtype C has actually prevailed over subtype $\mathrm{B}$ outside the capital cities of southern Brazil, and in fact may have been introduced into the country through Rio Grande. Of note is the fact that Rio Grande is one of the largest seaports in Brazil and serves as the southernmost transportation hub to neighbouring countries. Although earlier studies in Uruguay, Argentina, Paraguay, and Bolivia have not detected cases of subtype C infection [26-28], a more recent study has documented subtype $\mathrm{C}$ strains in these countries [29]. Besides spreading from south to north as earlier proposed $[15,30]$, it is possible that subtype $\mathrm{C}$ is similarly spreading down throughout South Cone countries, reaching neighbouring nations towards the outermost south. Further investigation in these bordering regions is needed to evaluate the local impact of Brazilian subtype $\mathrm{C}$ in other south American HIV/AIDS epidemics.

The present study also showed that subtype C was introduced in Rio Grande later in the HIV/AIDS epidemic than subtype B. This has been evidenced by the lower mean genetic diversity found in both the PR and RT genes seen in subtype C when compared with subtype B. The same assumption was discussed in an earlier study in southern Brazil [31], and the present study data further corroborates such a hypothesis.

The finding that subtype $\mathrm{C}$ was more frequent among women merits consideration. It may reflect the introduction of subtype $\mathrm{C}$ coinciding temporally with the increasing feminization of the HIV epidemic in Brazil [17]. It may also reflect a relatively higher rate of the male to female transmission of subtype C compared with subtype B. The differential efficiency of infection among distinct subtypes, in particular with respect to the infection of Langerhans cells, has been suggested in earlier studies [32,33].

Our data do not answer the question as to why subtype C is able to prevail over other subtypes. It has been proposed that subtype $\mathrm{C}$ is actually less fit than subtype $\mathrm{B}$ in vitro [34], but these findings have not been corroborated in vivo. In the present study, even although the mean diagnosis times were not significantly different in both subtypes $\mathrm{B}$ and $\mathrm{C}$, it took longer for patients infected with subtype $C$ to start antiretroviral drug therapy and this was probably postponed because of a slower clinical progression according to CDC criteria. It is possible that this longer asymptomatic phase seen in subtype C-infected patients makes its epidemic dissemination more efficient than that of subtype B, and could explain the epidemiological predominance of subtype C. However, HIV sexual transmission during the asymptomatic phase is eight to 10 times less likely than in acute infections [35], and this might not be epidemiologically relevant.
With regard to resistance mutations to antiretroviral drugs, no resistant isolates to all three classes of antiretroviral drugs among treated subjects were observed, a finding similar to other studies in Brazil $[16,36]$. The fact that there were almost no treatmentnaive patients infected with resistance mutation viruses corroborates recent low estimates of primary (transmitted) resistance in Brazil [37], and even in the state of Rio Grande do Sul [16].

In addition to the small sample size that provides low power to many comparisons, we recognize other limitations of our study. The use of subjects with HIV/AIDS in care raises the question of how representative our sample is to the larger epidemic. Nonetheless, the care unit sampled follows a large proportion of all cases in Rio Grande. Another limitation is determining the patients' timing of infection. In the present study, we are forced to rely on imperfect markers for the timing of infection, including the date of diagnosis, stage of disease, immunological stage, and age. New assays to detect recent infection, such as the BED capture enzyme immunoassay [38], may help with the interpretation of data from newly diagnosed patients.

Despite limitations, our data provide useful public health information. HIV heterosexual prevention policies should be stressed in southern Brazilian states, where higher rates of subtype $\mathrm{C}$ can be found and are now prevailing over the other variants. It is worth highlighting the fact that the southern region is the only one in the country where the HIV/AIDS epidemic has been increasing [39], and the association of this growth and subtype $\mathrm{C}$ virus should be further investigated. A rapid, stronger response to the HIV/AIDS epidemic in southern Brazil should be taken to prevent the emergence of another focus for the epidemic spread of this subtype, as seen in several countries of sub-Saharan Africa and south-east Asia.

\section{Acknowledgements}

The authors are deeply indebted to University Hospital FURG HIV/AIDS Unit staff for their help with data collection and the clinical follow-up of patients. They would also like to thank Professor Rodrigo Brindeiro (UFRJ) for his support to this study and Mônica Arruda and Adriana Afonso (UFRJ) for their technical support. The study was part of the $\mathrm{PhD}$ thesis of E.A.J.M.S., granted by the Coordination of Scientific Improvement in Universities.

Sponsorship: This study was funded by the Brazilian Ministry of Health STD/AIDS Program and Research Support Foundations of the state of Rio de Janeiro and Rio Grande do Sul. 


\section{References}

1. Esparza J, Bhamarapravati N. Accelerating the development and future availability of HIV-1 vaccines: why, when, where, and how? Lancet 2000; 355:2061-2066.

2. Wainberg M. HIV-1 subtype distribution and the problem of drug resistance. AIDS 2004; 18 (Suppl. 3):S63-S68

3. Novitsky VA, Montano MA, McLane MF, Renjifo B, Vannberg F, Foley $\mathrm{BT}$, et al. Molecular cloning and phylogenetic analysis of human immunodeficiency virus type I subtype C: a set of 23 full-length clones from Botswana. / Virol 1999; 73:4427-4432.

4. Renjifo B, Chaplin B, Mwakagile M, Shah P, Vamberg F, Msamanga G, et al. Epidemic expansion of HIV type 1 subtype $C$ and recombinant genotypes in Tanzania. AIDS Res Hum Retroviruses 1998; 14:635-638.

5. van Harmelen JH, Wood R, Lambrick M, Rybicki EP, Williamson $\mathrm{AL}$, Williamson $\mathrm{C}$. An association between $\mathrm{HIV}$-1 subtypes and mode of transmission in Cape Town, South Africa. AIDS 1997: 11:81-87.

6. van Harmelen JH, Van der Ryst E, Loubser AS, York D, Madurai $S$, Lyons $S$, Wood $R$, et al. A predominantly HIV-1 subtype C-restricted epidemic in South African urban populations. AIDS Res Hum Retroviruses 1999; 15:395-398.

7. Neilson JR, John GC, Carr JK, Lewis P, Kreiss JK, Jackson S, et al. Subtypes of human immunodeficiency virus type 1 and disease stage among women in Nairobi, Kenya. J Virol 1999; 73:43934403 .

8. Robbins KE, Kostrikis LG, Brown TM, Anzala O, Shin S, Plummer FA, et al. Genetic analysis of human immunodeficiency virus type 1 strains in Kenya: a comparison using phylogenetic analysis and a combinatorial melting assay. AIDS Res Hum Retroviruses 1999; 15:329-335.

9. Shankarappa R, Chatterjee R, Learn GH, Neogi D, Ding M, Roy $P$, et al. Human immunodeficiency virus type 1 env sequences from Calcutta in Eastern India: identification of features that distinguish subtype $\mathbf{C}$ sequences in India from other subtype $\mathbf{C}$ sequences. / Virol 2001; 75:10479-10487.

10. Bollinger RC, Tripathy SP, Quinn TC. The human immunodeficiency virus epidemic in India: current magnitude and future projections. Medicine (Baltimore) 1995; 74:97-106.

11. Rodenburg CM, Li Y, Trask SA, Chen Y, Decker J, Robertson DL, et al. Near full-length clones and reference sequences for subtype $C$ isolates of HIV type 1 from three different continents. AIDS Res Hum Retroviruses 2001; 17:161-168.

12. Yu XF, Chen J, Shao Y, Beyrer C, Lai S. Two subtypes of HIV-1 among injection-drug users in southern China. Lancet 1998; 351:1250.

13. Fontanet $\mathrm{AL}$, Messele $\mathrm{T}$, Dejene $\mathrm{A}$, Enquselassie $\mathrm{F}$, Abebe $\mathrm{A}$ Cutts FT, et al. Age- and sex-specific HIV-1 prevalence in the urban community setting of Addis Ababa, Ethiopia. AIDS 1998 12:315-322.

14. UNAIDS/WHO. Report on the global AIDS epidemic - update 2003. Geneva, Switzerland: UNAIDS; 2004.

15. Soares MA, De Oliveira T, Brindeiro RM, Diaz RS, Sabino EC Brigido $L$, et al. A specific subtype $\mathbf{C}$ of human immunodeficiency virus type 1 circulates in Brazil. AIDS 2003; 17:11-21.

16. Soares EA, Santos RP, Pellegrini JA, Sprinz E, Tanuri A, Soares $M A$. Epidemiologic and molecular characterization of human immunodeficiency virus type 1 in southern Brazil. I Acquir Immune Defic Syndr 2003; 34:520-526.

17. Szwarcwald CL, Bastos FI, Esteves MA, de Andrade CL. The spread of the AIDS epidemic in Brazil from 1987 to 1996: spatial analysis. Cad Saude Publica 2000· 16 (Suppl. 1):7-19.

18. Martinez AM, Barbosa EF, Ferreira PC, Cardoso FA, Silveira J, Sassi G, et al. Molecular epidemiology of HIV-1 in Rio Grande, RS, Brazil. Rev Soc Bras Med Trop 2002; 35:471-476.

19. Stuyver L, Wyseur A, Rombout A, Louwagie I, Scarcez T, Verhofstede $C$, et al. Line probe assay for rapid detection of drug-selected mutations in the human immunodeficiency virus type 1 reverse transcriptase gene. Antimicrob Agents Chemother 1997: 41:284-291.

20. Thompson JD, Higgins DG, Gibson TJ. CLUSTAL W: improving the sensitivity of progressive multiple sequence alignment through sequence weighting, position-specific gap penalties and weight matrix choice. NuCl Acids Res 1994; 22:4673-4680.
21. Kumar S, Tamura K, Jakobsen IB, Nei M. MEGA2: molecular evolutionary genetics analysis software. Bioinformatics 2001; 17:1244-1245.

22. Li W-H. Unbiased estimation of the rates of synonymous and nonsynonymous substitution. J Mol Evol 1993; 36:96-99.

23. Rhee SY, Gonzales MJ, Kantor R, Betts BJ, Ravela J, Shafer RW. Human immunodeficiency virus reverse transcriptase and protease sequence database. Nucl Acids Res 2003; 31:298303.

24. Johnson VA, Brun-Vezinet F, Clotet B, Conway B, D'Aquila RT, Demeter LM, et al. Drug resistance mutations in HIV-1. Top HIV Med 2003: 11:215-221.

25. Martínez AMB, Lopes A, Mendoza-Sassi R, Da Hora V, Soares EAJM, D'Ávila N, et al. Prevalence of subtype $C$ of human immunodeficiency virus type 1 and its influence on mother-tochild transmission in the city of Rio Grande, RS, Brazil. In: Vth Brazilian Symposium on HIV/AIDS Research. Rio de Janeiro, Brazil, 23-26 November 2003. [abstract 51].

26. Russell KL, Carcamo C, Watts DM, Sanchez J, Gotuzzo E, Euler $\mathrm{A}$, et al. Emerging genetic diversity of HIV-1 in South America. AIDS 2000; 14:1785-1791.

27. Espinosa A, Vignoles M, Carrillo MG, Sheppard H, Donovan R, Peralta LM, et al. Intersubtype BF recombinants of HIV-1 in a population of injecting drug users in Argentina. I Acquir Immune Defic Syndr 2004; 36:630-636.

28. Hierholzer J, Montano S, Hoelscher M, Negrete M, Hierholzer M, Avila MM, et al. Molecular epidemiology of HIV type $\mathbf{1}$ in Ecuador, Peru, Bolivia, Uruguay, and Argentina. AIDS ReS Hum Retroviruses 2002; 18:1339-1350.

29. Carrion G, Eyzaguirre L, Montano SM, Laguna-Torres V, Serra M, Aguayo N, et al. Documentation of subtype C HIV type 1 strains in Argentina, Paraguay, and Uruguay. AIDS Res Hum Retroviruses 2004: 20:1022-1025.

30. Brindeiro RM, Diaz RS, Sabino EC, Morgado MG, Pires IL, Brigido $\mathrm{L}$, et al. Brazilian network for HIV drug resistance surveillance (HIV-BResNet): a survey of chronically infected individuals. AIDS 2003; 17:1063-1069.

31. Guimaraes ML, dos Santos Moreira A, Loureiro R, GalvaoCastro B, Morgado MG, and the Brazilian Network for HIV Isolation and Characterization. High frequency of recombinant genomes in HIV type 1 samples from Brazilian southeastern and southern regions. AIDS Res Hum Retroviruses 2002; 18:1261-1269.

32. Soto-Ramirez LE, Renjifo B, McLane MF, Marlink R, O'Hara C, Sutthent R, et al. HIV-1 Langerhans' cell tropism associated with heterosexual transmission of HIV. Science 1996; 271:1291-1293.

33. Pope M, Ho DD, Moore JP, Weber J, Dittmar MT, Weiss RA. Different subtypes of HIV-1 and cutaneous dendritic cells. Science 1997; 278:786-788.

34. Ball SC, Abraha A, Collins KR, Marozsan AJ, Baird H, QuinonesMateu ME, et al. Comparing the ex vivo fitness of CCR5-tropic human immunodeficiency virus type 1 isolates of subtypes B and C. J Virol 2003; 77:1021-1038.

35. Pilcher CD, Tien HC, Eron JJ Jr, Vernazza PL, Leu SY, Stewart PW, et al. Brief but efficient: acute HIV infection and the sexual transmission of HIV. I Infect Dis 2004; 189. 1785-1792.

36. Caride $E$, Brindeiro $R$, Hertogs $K$, Larder B, Dehertogh $P$, Machado $E$, et al. Drug-resistant reverse transcriptase genotyping and phenotyping of $B$ and non-B subtypes ( $F$ and $A$ ) of human immunodeficiency virus type I found in Brazilian patients failing HAART. Virology 2000; 275:107-115.

37. Soares MA, Brindeiro RM, Tanuri A. Primary HIV-1 drug resistance in Brazil. AIDS 2004; 18 (Suppl. 3):S9-S13.

38. Hu DJ, Vanichseni S, Mock PA, Young NL, Dobbs T, Byers RH $\mathrm{Jr}$, et al. HIV type $\mathbf{1}$ incidence estimates by detection of recent infection from a cross-sectional sampling of injection drug users in Bangkok: use of the IgG capture BED enzyme immunoassay. AIDS Res Hum Retroviruses 2003; 19:727-730.

39. National Program on STD/AIDS, Brazilian Ministry of Health, Brazil. Epidemiologic Bulletin - AIDS. Year XVII no. 01. April to December; 2003. 